\title{
Dificuldades e Potencialidades de Líderes Introvertidos em uma Indústria de Eletrodomésticos: um Estudo de Caso
}

\section{Difficulties and Potentialities of Leaders Introverted in a Home Appliance Industry: A Case Study}

Dificultades y Potencialidades de Los Líderes Introvertidos en una Industria de Electrodomésticos: Un Estudio de Caso

Rayane Pinto Tavares ${ }^{1}$ rayane.tavares.rt@gmail.com http://lattes.cnpq.br/9607781201779741 https://orcid.org/0000-0003-1838-0358

Fabiula Meneguete Vides da Silva ${ }^{1}$ fabiulamv@yahoo.com.br http://lattes.cnpq.br/1562017815638375 https://orcid.org/0000-0001-6073-4506

Universidade Federal do Amazonas, UFAM, Brasil ${ }^{1}$

Recebido em: 21/09/2020 / Revisão: 09/01/2021 / Aprovado em: 05/02/2021

Editores responsáveis: Prof. Dr. Antônio Giovanni Figliuolo Uchôa e Prof. Dr. Jonas Fernando Petry Processo de Avaliação: Double Blind Review DOI: https://10.47357/ufambr.v3i1.8143 
Dificuldades e Potencialidades de Líderes Introvertidos em uma Indústria de Eletrodomésticos: um Estudo de Caso

\title{
Resumo
}

O objetivo deste trabalho é analisar as dificuldades e potencialidades do líder introvertido em uma indústria de eletrodomésticos. O presente artigo é fundamentado nos moldes de uma pesquisa qualitativa. A população engloba dez pessoas nos respectivos cargos: líderes, supervisores e gerentes da organização. Relevante ressaltar que embora nem todas as nomenclaturas dos cargos contenha a expressão liderança ou líderes, os sujeitos pesquisados exercem atividade de líderes. Os dados foram coletados por meio de entrevista semiestruturada e, para interpretação, foi utilizada a análise de conteúdo. Recorrendo às análises, constatou-se que os líderes introvertidos são minoria uma vez que, do universo estudado, três líderes foram identificados. A percepção deles é voltada à valorização do ser humano e possuem a capacidade de ouvir e ter empatia. Como pontos a melhorar, podem-se destacar a dificuldade de aproximação com os demais colegas de trabalho, de cultivar amizades e a falta de valorização própria. Descobrir essas características possibilitou conhecer este perfil pouco valorizado e compreender que estes podem ser excelentes líderes tão somente por possuírem o perfil introvertido.

Palavras-chaves: Liderança. Introversão. Extroversão.

\section{Difficulties and Potentialities of Leaders Introverted in a Home Appliance Industry: A Case Study}

\begin{abstract}
The objective of this work is to analyze the difficulties and potential of the introverted leader in a home appliance industry. This article is based on a qualitative research model. The population comprises ten people in their respective positions: leaders, supervisors and managers of the organization. It is important to note that although not all job nomenclatures contain the expression leadership or leaders, the subjects surveyed exercise the activity of leaders. Data were collected through semi-structured interviews and, for interpretation, content analysis was used. Using the analysis, it was found that introverted leaders are a minority since, from the universe studied, three leaders were identified. Their perception is focused on valuing the human being and they have the ability to listen and empathize. As points to improve, we can highlight the difficulty of getting closer to other co-workers, of cultivating friendships and the lack of self-worth. Discovering these characteristics made it possible to know this low-valued profile and understand that they can be excellent leaders just because they have an introverted profile.
\end{abstract}

Keywords: Leadership. Introversion. Extroversion.

\section{Dificultades y Potencialidades de Los Líderes Introvertidos en una Industria de Electrodomésticos: Un Estudio de Caso}

\section{Resumen}

El objetivo de este trabajo es analizar las dificultades y potencialidades del líder introvertido en una industria de electrodomésticos. Este artículo se basa en un modelo de investigación cualitativa. La población está compuesta por diez personas en sus respectivos cargos: líderes, supervisores y gerentes de la organización. Es importante señalar que, aunque no todas las nomenclaturas laborales contienen la expresión liderazgo o líderes, los sujetos encuestados ejercen la actividad de líderes. Los datos se recolectaron a través de entrevistas semiestructuradas y, para la interpretación, se utilizó el análisis de contenido. Utilizando el 
Dificuldades e Potencialidades de Líderes Introvertidos em uma Indústria de Eletrodomésticos: um Estudo de Caso

análisis, se encontró que los líderes introvertidos son una minoría ya que, del universo estudiado, se identificaron tres líderes. Su percepción está enfocada a valorar al ser humano y tienen la capacidad de escuchar y empatizar. Como puntos a mejorar, podemos destacar la dificultad de acercarse a otros compañeros de trabajo, de cultivar amistades y la falta de autoestima. Descubrir estas características hizo posible conocer este perfil de baja valoración y entender que pueden ser excelentes líderes solo porque tienen un perfil introvertido.

Palabras clave: Liderazgo. Introversión. Extroversión. 
Dificuldades e Potencialidades de Líderes Introvertidos em uma Indústria de Eletrodomésticos: um Estudo de Caso

\section{INTRODUÇÃO}

Face à globalização, em que os mercados são altamente competitivos, complexos e dinâmicos, as organizações devem ter capacidade de adaptação contínua em seus processos e produtos (Loureiro, 1999). Para Sugahara, Jannuzzi e Falsarella (2018) a inovação assume papel fundamental, pois permite a reestruturação dos processos e produtos melhorando o desempenho competitivo das organizações. Desta forma, para gerir toda essa mudança, novas atitudes de líderes e gestores são requeridas, fazendo-os repensar o conceito de gestão de pessoas, deixando de lado o tradicionalismo ineficiente e voltando-se para a valorização do capital humano (Fisher, 2001).

As empresas estão em busca de profissionais alinhados aos seus objetivos organizacionais que possam desenvolver e crescer conjuntamente, mas, para isso, é preciso que haja líderes com capacidade de influenciar, trabalhar entusiasticamente objetivando atingir metas em comum (Hunter, 2004).

Um dos maiores especialistas em personalidade humana destacou duas formas de atitudesdisposições das pessoas em relação ao objeto: de um lado, prefere focar a sua atenção no mundo exterior para pessoas e fatos (extroversão); do outro, direciona para o mundo interno de representações psíquicas no significado (introversão). O conceito de ambos se baseia na maneira como se processa o movimento de energia psíquica (libido) em relação ao objeto, ou seja, como recarregam sua energia e como algumas dessas atitudes irão direcionar a personalidade, seja à objetividade ou à subjetividade (Jung, 1971).

Extrovertidos tendem a tomar decisões e executar tarefas rapidamente, sentem-se confortáveis com muitas tarefas simultâneas e em correr riscos. Gostam da "excitação da caça" por recompensas como dinheiro e status. Introvertidos por vezes trabalham de forma mais lenta e ponderada. Eles gostam de focar em uma tarefa de cada vez e podem ter grande poder de concentração. São relativamente imunes às tentações da fama e fortuna (Cain, 2012).

Para Cain (2012) existe um Ideal de extroversão, onde há supervalorização dos líderes com discursos eloquentes, sendo considerados mais inteligentes, competentes e simpáticos. Esse estilo passou a ser tão atraente e transformou-se num padrão para quem quer ter sucesso, em que a extroversão sobrepuja a introversão. Dessa forma, surge a pergunta: como líderes introvertidos têm se adaptado ao ambiente organizacional que potencializa os líderes extrovertidos? No intuito de responder a questão, o objetivo geral é analisar as dificuldades e potencialidades do líder introvertido em uma indústria de eletroeletrônicos. Para atingi-lo, os seguintes objetivos específicos foram definidos: identificar quais gestores possuem o perfil introvertido; investigar e descrever como é a percepção da gestão sobre o perfil introvertido; e verificar quais as facilidades e dificuldades que o perfil introvertido encontra.

$\mathrm{O}$ presente artigo é fundamentado nos moldes de uma pesquisa qualitativa. A população engloba dez pessoas nos respectivos cargos: líderes, supervisores e gerentes de uma indústria. Todos os profissionais que fizeram parte do estudo exercem a função de liderança. Os dados foram coletados por meio de entrevista semiestruturada e, para interpretação, foi utilizada a análise de conteúdo. Na seção 2, tem-se o referencial teórico; na seção 3, são descritos os aspectos metodológicos do estudo; na 4, os dados coletados são apresentados e discutidos; e, por fim, na seção 5, estão presentes as considerações finais da pesquisa.

\section{REFERENCIAL TEÓRICO}


Dificuldades e Potencialidades de Líderes Introvertidos em uma Indústria de Eletrodomésticos: um Estudo de Caso

Nesta seção são apresentadas as abordagens da literatura sobre gestão de pessoas, liderança, liderança introvertida, os conceitos de introversão e extroversão e suas singularidades.

\subsection{Liderança}

O conceito de liderança expõe diversas abordagens sob os mais variados pontos de vista, inclusive em situações incompreendidas e, por vezes, contraditórias (Bergamini, 1994). Alves (2010) afirma que é uma definição de difícil compreensão com várias interpretações, atuando nas mais diversas áreas do conhecimento. $\mathrm{O}$ estudo do processo de liderança, na maioria das vezes associado a mudanças, envolve proporções tais como subjetividade, objetividade e agente-estrutura. $\mathrm{O}$ conceito da liderança é fluido, complexo e não há uma definição amplamente aceita (Peretomode, 2012).

Os conceitos a respeito da liderança ultrapassam toda a literatura de ciências sociais aplicadas, os quais se evidenciam: liderança envolve relação de influência entre o indivíduo e o grupo; o líder revela suas habilidades inerentes; para se compreender a liderança é recomendável estudar a personalidade e o comportamento de líderes reconhecidos e descrever os seus traços característicos e a sua forma de agir; processo de motivar a equipe em busca dos objetivos estabelecidos; a atuação do líder depende do contexto; o relacionamento entre líder e liderados é baseado em recompensas abstratas e concretas em função do desempenho grupal; liderança refere-se à capacidade do líder em gerar contentamento pelos resultados obtidos (Bergamini, 2015; Crainer, 2006; Spector, 2005; Vergara, 2003). Neste sentido, destacam-se as teorias de liderança de acordo com seu enfoque: dos traços, dos estilos, situacional e transformacional.

A teoria dos traços buscou diferenciar traços de líderes e não líderes, afirmando que os primeiros nasciam ou adquiriam essas características principalmente das pessoas da alta classe. Kirkpatrick e Locke (1991) ressaltam traços como desejo de liderar, direção, honestidade e integridade, autoconfiança, habilidade cognitiva e conhecimento dos negócios. Bowditch e Buono (2002) destacam que esta teoria enfatizava, de forma especial, as qualidades pessoais do líder, partindo da pressuposição de que deveriam possuir determinadas características na personalidade, facilitando, assim, o desempenho de seu papel. Essa teoria predominou com êxito até a década de 1940. A abordagem dos traços foi frustrada uma vez que as pesquisas não validaram a combinação das características que distinguia pertinentemente os líderes eficazes dos não eficazes, revelaram apenas que não existem traços universais e que este serve mais para prever a liderança do que para distinguir os eficazes dos não eficazes (Robbins, 2014).

A teoria dos estilos de liderança surgiu na década de 1950, dando ênfase à abordagem comportamental. Segundo Benevides (2010), essas teorias tornaram-se muito mais estimulantes uma vez que trouxeram a perspectiva de desenvolvimento de líderes, já não mais considerados natos ou inatos conforme preconizava a teoria dos traços. A formação de líderes tornou-se uma atividade importante, pois, através dela, poder-se-iam modificar e adaptar comportamentos (Stefano, Andrade, Gonçalves \& Valori, 2008). Nesse sentido, a liderança pode ser aprendida através de técnicas de desenvolvimento pessoal, mudando a afirmação anterior de que a liderança somente era herdada. Este estilo é voltado para o ser racional, emocional, democrático, autoritário, orientado para tarefas ou pessoas (Rezende, Carvalho Neto \& Tanure, 2014). Desta maneira, observa-se o comportamento do líder frente a seus subordinados e em como ele age nos grupos de trabalho eficazes e ineficazes, com o objetivo de encontrar padrões de comportamentos específicos que caracterizem tal estilo (Champoux, 2011). 
Dificuldades e Potencialidades de Líderes Introvertidos em uma Indústria de Eletrodomésticos: um Estudo de Caso

Na perspectiva da teoria situacional, Fiedler (1967) propõe que as condições da eficácia da liderança associem-se a três dimensões contingenciais ou situacionais: a) o grau de confiança nas relações entre líderes e liderados; b) a estrutura da tarefa; e c) a posição do líder. Desse modo, a influência do líder será maior se ele mantiver relações respeitosas com seus liderados, isto é, que os levem a ter confiança. Essas variáveis situacionais classificarão se uma determinada situação favorável ou não, permitirá o líder exercer influência, não sendo um modelo absoluto, pois estão suscetíveis as variações do meio e as implicações da análise situacional (Ramos, Corrêa, Silva, Pereira, Lemes, \& Magalhães, 2016).

Muitos autores ajudaram na abordagem dessa teoria, mas o precursor, House (1971), elaborou a teoria caminho-objetivo, na qual orienta o comportamento do líder para atuar sobre as variáveis motivacionais, conduzindo seus subordinados à conquista dos resultados organizacionais.

Hersey e Blanchard (1986), partindo do estudo de Tannembaum e Schmidt, identificaram dois tipos de comportamento do líder: voltado à tarefa (autocrático) e às relações interpessoais (democrático) e a Teoria do Desenvolvimento Psicológico, pela qual o indivíduo nasce imaturo e direciona-se para o amadurecimento. Os pesquisadores sugerem que o estilo de liderança deve variar de acordo com a maturidade dos subordinados em relação à tarefa a ser realizada. A combinação em determinar, persuadir, compartilhar e delegar faz parte da tarefa e do relacionamento. Desta forma, o líder precisa se adaptar ao fazer um diagnóstico dos subordinados para identificar se estão seguindo rumo aos objetivos. Esses estilos autocrático e democrático vêm sendo aperfeiçoado nas organizações e variadas mudanças ocorridas no comportamento dos líderes trouxeram resultados surpreendentes e altamente positivos no desempenho das equipes por serem os mediadores na condução das atividades em prol de um objetivo (Dorneles, Salvagni \& Nodari, 2017).

A teoria transformacional e transacional relacionam-se ao comportamento organizacional do líder durante períodos de mudança e a forma pela qual ele elabora processos de criação de visões de um estado futuro desejado para a obtenção do comprometimento do empregado em contextos de mudança (Sadler, 2003). Ambas as teorias, em situações diferentes podem ser mais efetivas: enquanto o líder transformacional consegue melhores resultados em períodos de criação de uma empresa e de mudança, o líder transacional tem melhor desempenho em fases de evolução lenta em ambientes mais estáveis (Morais, 2016).

O principal objetivo da liderança transformacional é proporcionar ao liderado um ambiente organizacional harmonioso, no qual ele possa desenvolver seu potencial e, consequentemente, a melhoria de seu desempenho. Esse tipo de liderança procura aumentar a consciência do grupo através do estímulo do crescimento individual, buscando alinhar mais as expectativas individuais e organizacionais (Bass, 1985).

Benevides (2010, p. 37) aponta que o líder transformacional "compartilha riscos com seus seguidores e é consistente com a conduta ética, princípio e valores definidos". Para Burns (2003), a liderança transformacional influencia o desenvolvimento de valores de equipes baseados em princípios e propósitos. Em contrapartida, a liderança transacional permanece com a cultura estável, ênfase nas trocas entre trabalho e recompensa/punição, em relações por contrato, métodos e técnicas. 
Dificuldades e Potencialidades de Líderes Introvertidos em uma Indústria de Eletrodomésticos: um Estudo de Caso

A principal característica da liderança transformacional, segundo Bass e Avolio (1994), é a consideração individualizada, dada às necessidades do liderado e o cuidado quanto ao seu desenvolvimento. Posteriormente, a estimulação intelectual: o líder que estimula e influencia a mudança de ideia. Em seguida, é a inspiração motivacional, que o leva a encontrar novas oportunidades e possibilidades. A última é o carisma, resultante da confiança, admiração, consideração e identificação dos liderados com os líderes.

Assim, é visível que as teorias estão em construção: a teoria dos traços destaca a liderança como inata; a comportamental aborda como os líderes agem com seus liderados; a situacional depende da tríplice líder-liderado-tarefa; e a transformacional define a importância do líder carismático no desenvolvimento e motivação de seus liderados.

Na sequência discorre-se sobre o tema extroversão e introversão, para que se possa dissertar, por último, nessa seção, acerca da liderança introvertida.

\subsection{Extroversão versus Introversão}

Um dos primeiros estudiosos referentes ao tema extroversão e introversão foi Jung (1971), destacando duas formas de atitudes/disposições das pessoas em relação ao objeto. Enquanto focou, de um lado, a sua atenção no mundo exterior para pessoas e fatos (extroversão), do outro, para o mundo interno de representações psíquicas (introversão). Tanto a extroversão quanto a introversão baseiam-se na maneira como se processa o movimento de energia psíquica (libido) em relação ao objeto, ou seja, como recarregam sua energia e como umas dessas atitudes irá direcionar a personalidade, seja à objetividade ou à subjetividade. Seus estudos afirmam que não existe uma pessoa puramente introvertida ou extrovertida, porém há uma inclinação maior para um dos traços.

A contraposição entre introversão e extroversão, segundo o autor, está relacionada à maneira como captam as informações do ambiente externo, mostrando suas preferências para a tomada de decisões e o julgamento acerca de objetos, pessoas, acontecimentos etc.

Um estudo publicado pela revista Frontiers in Human Neuroscience mostrou que os introvertidos e extrovertidos processam experiências nos centros de recompensa do cérebro de maneira diferente. Enquanto os extrovertidos sentem a dopamina relacionada ao ambiente, os introvertidos tendem a não sentir essa alteração fisiológica porque não processam as recompensas com a mesma intensidade (Ghose, 2013).

Pessoas extrovertidas são sociáveis, expansivas, falantes, socialmente acessíveis, gregárias e confiantes. Sentem-se mais confortáveis na companhia de um grupo de pessoas do que sozinhas, energizam-se no contato com os outros. O silêncio e o isolamento esgotam-nas. Tendem a não serem boas ouvintes, pois sempre estão ansiosas para falar aos outros o que têm em mente. Têm o interesse voltado ao mundo externo, a ações e conquistas práticas, a condições objetivas. Agem do fazer para o pensar e voltam a fazer; são indivíduos que pensam depois, que entendem a vida depois de vivê-la. Entregam-se a experiências novas e não exploradas. São menos passionais e descarregam suas emoções conforme vão surgindo (Ponte, 2012). 
Dificuldades e Potencialidades de Líderes Introvertidos em uma Indústria de Eletrodomésticos: um Estudo de Caso

Pessoas introvertidas, por sua vez, são quietas, reservadas, sutis, questionadoras e prezam pela privacidade. Tendem a segurar as palavras, ouvem cuidadosamente o que as outras pessoas dizem. Parecem isoladas ou retraídas, sentindo-se mais confortáveis quando sozinhas ou com poucas pessoas (o contato com muitas pessoas tende a ser cansativo). Sentem-se energizadas quando trabalham de forma solitária e silenciosa. Essas características causam certa hesitação quanto à vida. Possuem maior facilidade de expressão no campo da escrita e sua vida interior é rica em imagens e impressões. Não conseguem viver a vida depois de entendê-la; seguem-na do pensar para o fazer e voltam a pensar posteriormente. São mentes dirigidas para o próprio interior, a condições subjetivas: intensos e passionais, os introvertidos reprimem suas emoções e guardam-nas (Ponte, 2012).

Granneman (2017) ressalta que tanto o introvertido como o extrovertido podem sentir timidez. Contudo, embora não seja fatídico, na maioria das vezes, as pessoas associam a timidez à introversão como se fossem a mesma coisa. Apesar de evitarem interações sociais, as razões pelas quais o fazem são diferentes. Enquanto os introvertidos sentem-se cansados, os tímidos tendem a sentir angústia, vergonha. Costuma observar-se mais a timidez nos introvertidos e isso pode ter relação com os sinais que recebem da sociedade de que as pessoas preferem as personalidades extrovertidas. Por conta disso, aqueles sentem-se mal por pensarem demais e precisarem de mais tempo para refletir, o que pode levar à timidez por conta do medo e do julgamento.

Nota-se que a timidez é um sentimento daquele (a) que não gosta de ser exposto diante do julgamento das pessoas e por conta disso, pode ocasionar um comportamento mais defensivo., Mello (2013) afirma que o medo está presente em todas as pessoas introvertidas e extrovertidas. Essa defesa natural e instintiva faz-se notória no cotidiano. $\mathrm{O}$ fato é que o medo é uma ótima base para decisões e é recorrente em todas as situações cotidianas.

A seguir serão apresentados alguns estudos que abordam a temática liderança introvertida para que possamos compreender a temática principal do presente estudo.

\subsection{Liderança Introvertida e Extrovertida}

Extrovertidos tendem a tomar decisões e executar tarefas rapidamente por sentirem-se confortáveis com muitas tarefas ao mesmo tempo e em correr riscos. Gostam da "excitação da caça" por recompensas como dinheiro e status. Introvertidos muitas vezes trabalham de forma mais lenta e ponderada. Seu foco é voltado a uma tarefa de cada vez e podem ter um grande poder de concentração. São relativamente imunes às tentações da fama e fortuna (Cain, 2012). As potencialidades da introversão são marcadas pelo lado humano, valorizando as pessoas. São, por isso, ótimos ouvintes e têm facilidade na manutenção da calma em momentos de estresse, sabendo planejar ações para tomar iniciativa no momento certo. São organizados, dedicados e persistentes na realização de tarefas (Costa, 2015).

Segundo Nobel (2010), presume-se que pessoas quietas e falantes tenham o mesmo número de ideias boas e más, mas a percepção que se tem, em geral, é de que as falantes são mais inteligentes do que as quietas, o que é equivocado. Moutafi (2003) assevera que o introvertido tem melhor performance que os extrovertidos. Para Moutafi, (2003) no teste de Watson-Glaser de pensamento crítico, uma avaliação amplamente utilizada nos mundos dos negócios para 
Dificuldades e Potencialidades de Líderes Introvertidos em uma Indústria de Eletrodomésticos: um Estudo de Caso

promoções e contratações, os introvertidos demonstram excelência em resolução de problemas. A pesquisa sobre a capacidade de liderança introvertida e extrovertida, liderada por Gino (2015) juntamente a Adam Grant e David Hofmann e feita em uma cadeia de pizzarias nos EUA, concluiu que líderes introvertidos podem ser menos eficientes que os extrovertidos quando lideram funcionários passivos. Porém, quando comandam uma equipe proativa, tendem a apresentar um desempenho superior por serem ótimos ouvintes e levarem em consideração as sugestões apresentadas pelos colaboradores. O resultado da pesquisa demonstra que estes líderes têm a habilidade de trazer o que há de melhor nas pessoas. No entanto, não conseguem aplicar todo o seu potencial devido ao que Cain (2012) afirma sobre ideal de extroversão, que valoriza aquele com discurso eloquente, carismático e sociável. Desta forma, costumam sentir necessidade de ajustar sua personalidade, o que pode acarretar perdas tanto para eles quanto para a empresa.

A pesquisa realizada por Collins (2013) sobre as companhias de alto desempenho do fim do século XX, crescendo o triplo da média de seus concorrentes por pelo menos 15 anos e conduzidas por líderes, classificada pelo nível 5, aqueles conhecidos não pelo carisma, mas pela extrema humildade e esforço, possuíam como características: preferência por escutar pontos de vista antes de tomar decisões, valorizando a tarefa de cada membro da equipe e reconhecendo o desempenho de cada colaborador e que evitam falar de si mesmos. Líderes que, mesmo quietos, encontraram maneiras de sobressaírem-se apesar de não terem uma personalidade extrovertida em construírem e conduzirem a empresa - e não o próprio ego.

Assim, não existe espaço para desperdiçar pessoas com potencial elevado e que podem contribuir com eficiência para o sucesso das organizações. Ambas as características precisam ter as mesmas oportunidades em mostrar suas habilidades e seu interesse pelos negócios da empresa (Santos 2016).

\section{PROCEDIMENTOS METODOLÓGICOS}

Esta proposta fundamentou-se em uma pesquisa qualitativa uma vez que responde a questões muito particulares, relacionadas a um nível de realidade que não pode, ou não deveria ser, quantificado, mensurado. A interação entre pesquisador e o sujeito pesquisado é essencial, pois contempla o afetivo, o existencial, o contexto do dia a dia, as experiências e a linguagem do senso comum no ato da entrevista (Minayo, 2007).

A presente pesquisa caracterizou-se como um estudo de caso, uma vez que pretende compreender um fenômeno complexo da liderança e suas características. O estudo de caso é um método potencial de pesquisa quando se deseja entender um fenômeno social complexo em um grau de detalhamento das relações entre indivíduos e as organizações, bem como do meio nos quais estão inseridos (Yin, 2006).

A população desta análise foi composta por dez pessoas (entre líderes, supervisores e gerentes) que fazem parte da organização, de setores variados. Relevante ressaltar que embora nem todas as nomenclaturas dos cargos contenha a expressão liderança ou líderes, os sujeitos pesquisados exercem atividade de líderes, por tal razão, na sequência trata-se todos os sujeitos que fizeram parte da pesquisa como líderes, embora na organização os cargos tenham nomenclatura 
Dificuldades e Potencialidades de Líderes Introvertidos em uma Indústria de Eletrodomésticos: um Estudo de Caso

diferentes: líderes, supervisores e gerente). A escolha da Indústria X e dos líderes deu-se pela disponibilidade e facilidade de contato. Para Vergara (2005), a utilização do critério de acessibilidade é de longe um procedimento estático e seleciona elementos pela facilidade de acesso a eles.

Objetivando não identificar a organização objeto dessa análise, a mesma foi identificada com a expressão "Indústria X". Trata-se de uma indústria de médio porte do ramo eletroeletrônico, localizada na cidade de Manaus, possuindo aproximadamente 500 funcionários. Foi utilizada a entrevista semiestruturada para coletar os dados sobre liderança introvertida. Segundo Triviños (1994), esse tipo de entrevista parte de certos questionamentos básicos, apoiados em teorias e hipóteses que interessam à pesquisa e que oferecem um campo interrogativo fruto das respostas do informante. Desta forma, isso segue espontaneamente a linha de seu pensamento e de suas experiências dentro do foco principal colocado pelo pesquisador.

As entrevistas foram realizadas com dez líderes, dos quais apenas dois não autorizaram a gravação por não se sentirem à vontade. Os nomes dos entrevistados são fíctícios, garantindo o anonimato dos sujeitos entrevistados. Os entrevistados serão identificados pelos seguintes nomes fictícios: Renato, Carla, Lucas, Pedro, Ana, Paula, Marcos, Maria, Roberto e Gustavo. No quadro 1, podem-se observar algumas características dos sujeitos entrevistados, ressaltandose o tempo de empresa, área de atuação, faixa etária, escolaridade e formação profissional.

Quadro 1 - Perfil dos líderes

\begin{tabular}{|c|c|c|c|c|c|}
\hline Líder & $\begin{array}{l}\text { Tempo de } \\
\text { empresa }\end{array}$ & $\begin{array}{ll}\text { Área } & \text { de } \\
\text { atuação } & \\
\end{array}$ & $\begin{array}{l}\text { Faixa } \\
\text { etária }\end{array}$ & Escolaridade & $\begin{array}{ll}\text { Área } & \text { de } \\
\text { formação } & \end{array}$ \\
\hline Renato & 8 anos & Qualidade & 20 a 30 anos & Pós-graduado & $\begin{array}{l}\text { Engenharia } \\
\text { Elétrica }\end{array}$ \\
\hline Carla & 3 anos & Produção & 30 a 40 anos & Graduada & $\begin{array}{l}\text { Processos } \\
\text { Gerenciais }\end{array}$ \\
\hline Lucas & 8 anos & $\begin{array}{l}\text { Segurança } \\
\text { do Trabalho }\end{array}$ & 30 a 40 anos & Pós-graduado & Fisioterapia \\
\hline Pedro & 10 anos & Produção & 30 a 40 anos & Pós-graduado & $\begin{array}{l}\text { Administração } \\
\text { Gestão de } \\
\text { Serviços }\end{array}$ \\
\hline Ana & 5 anos & Produção & 30 a 40 anos & Graduada & Contabilidade \\
\hline Paula & 7 anos & Serviços & 40 a 50 anos & Graduada & $\begin{array}{l}\text { Gestão de } \\
\text { Segurança }\end{array}$ \\
\hline Marcos & 13 anos & Engenharia & 40 a 50 anos & Mestre & $\begin{array}{l}\text { Engenharia e } \\
\text { Gestão da } \\
\text { Produção }\end{array}$ \\
\hline Maria & 6 anos & $\begin{array}{l}\text { Segurança } \\
\text { do Trabalho }\end{array}$ & 40 a 50 anos & Mestre & $\begin{array}{l}\text { Engenharia } \\
\text { Ambiental }\end{array}$ \\
\hline Roberto & $\begin{array}{l}1 \text { ano e } 6 \\
\text { meses }\end{array}$ & $\begin{array}{l}\text { Tecnologia } \\
\text { da } \\
\text { Informação } \\
\end{array}$ & 40 a 50 anos & Mestre & $\begin{array}{l}\text { Engenharias } \\
\text { Civil e da } \\
\text { Computação }\end{array}$ \\
\hline Gustavo & 13 anos & Logística & $\begin{array}{l}\text { Acima de } 50 \\
\text { anos }\end{array}$ & Pós-graduado & $\begin{array}{l}\text { Engenharia } \\
\text { Elétrica }\end{array}$ \\
\hline
\end{tabular}


Dificuldades e Potencialidades de Líderes Introvertidos em uma Indústria de Eletrodomésticos: um Estudo de Caso

Fonte: as autoras (2019).

Vale destacar que, no quadro 1, todos os líderes possuem nível superior e que a quantidade de líderes com idade de 30 a 40 e 40 a 50 estão na mesma proporção, cuja maioria está há mais de 5 anos na empresa.

A coleta de dados foi realizada em duas partes, ambas realizadas durante duas semanas devido a disponibilidade dos líderes. Na primeira semana foi realizada uma entrevista semiestruturada com os líderes em geral. Na semana seguinte, foram entrevistados somente os líderes com perfil mais acentuado para a introversão, onde foram identificadas suas percepções, destacando os pontos positivos e negativos deste traço.

Inicialmente, foi realizada a transcrição dos dados daqueles que permitiram a gravação; após, a fim de analisar os dados primários através das entrevistas semiestruturadas, foi utilizada a análise de conteúdo, fundamentada na revisão bibliográfica realizada (Yin, 2006; Bardin, 2016).

\section{APRESENTAÇÃO E ANÁLISE DE DADOS}

O presente artigo analisou os dados coletados a partir das entrevistas realizadas com dez pessoas nos respectivos cargos: líderes, supervisores e gerentes da Indústria $X$, pertencentes a setores diferentes. Embora nem todas as nomenclaturas dos cargos contenha a expressão liderança ou líderes, os sujeitos pesquisados exercem atividade de líderes. A entrevista contemplou 7 questões, visando a investigar aspectos tais como: características que o líder deve possuir; atitudes a respeito da tomada de decisões; execução de tarefas; ambiente de trabalho; postura em reuniões; preferência sobre liderados e receptividade a sugestões.

\subsection{Identificação do perfil introvertido}

No intuito de identificar o líder introvertido, foram transcritas e compiladas as respostas de cada um dos entrevistados. As categorias características importantes para a liderança, tomada de decisão, execução de tarefas, ambiente de trabalho, postura em reuniões, liderados proativos ou reativos e abertura a sugestões foram baseadas em Cain (2012) e serão apresentadas no quadro 2.

Quadro 2: Aspectos da Liderança

\begin{tabular}{|c|c|c|c|c|c|c|c|}
\hline \multirow{2}{*}{ Líder } & $\begin{array}{c}\text { Característi- } \\
\text { cas } \\
\text { Importantes } \\
\text { para a } \\
\text { Liderança }\end{array}$ & $\begin{array}{c}\text { Tomada de } \\
\text { Decisão }\end{array}$ & $\begin{array}{c}\text { Execução } \\
\text { de } \\
\text { Tarefas }\end{array}$ & $\begin{array}{c}\text { Ambiente } \\
\text { de } \\
\text { Trabalho }\end{array}$ & $\begin{array}{c}\text { Postura } \\
\text { em } \\
\text { Reuniões }\end{array}$ & $\begin{array}{c}\text { Lidera- } \\
\text { dos } \\
\text { Proati- } \\
\text { vos ou } \\
\text { Reati- } \\
\text { vos }\end{array}$ & $\begin{array}{c}\text { Abertos } \\
\text { a } \\
\text { Sugestões }\end{array}$ \\
\hline
\end{tabular}


Dificuldades e Potencialidades de Líderes Introvertidos em uma Indústria de Eletrodomésticos: um Estudo de Caso

\begin{tabular}{|c|c|c|c|c|c|c|c|}
\hline Renato & $\begin{array}{c}\text { Acessível } \\
\text { Participativo } \\
\text { Conhecedor }\end{array}$ & $\begin{array}{c}\text { Reunir o máximo } \\
\text { de } \\
\text { informações }\end{array}$ & Não definiu & $\begin{array}{l}\text { Lugares } \\
\text { tranquilos }\end{array}$ & $\begin{array}{r}\text { Ouvir } \\
\text { primeiro }\end{array}$ & Ambos & Sim \\
\hline Carla & $\begin{array}{l}\text { Saber ouvir } \\
\text { Imparcial } \\
\text { Empático }\end{array}$ & $\begin{array}{c}\text { Reunir o máximo } \\
\text { de } \\
\text { informações }\end{array}$ & $\begin{array}{l}\text { Uma atividade } \\
\text { por vez }\end{array}$ & $\begin{array}{l}\text { Lugares } \\
\text { agitados }\end{array}$ & $\begin{array}{l}\text { Ouvir } \\
\text { primeiro }\end{array}$ & Proativo & $\operatorname{Sim}$ \\
\hline Lucas & $\begin{array}{c}\text { Objetivo } \\
\text { Comunicativ } \\
\text { o } \\
\text { Persistente }\end{array}$ & $\begin{array}{l}\text { Resolver de } \\
\text { imediato }\end{array}$ & $\begin{array}{l}\text { Terminá-las } \\
\text { rapidamente }\end{array}$ & $\begin{array}{l}\text { Lugares } \\
\text { agitados }\end{array}$ & $\begin{array}{l}\text { Expor } \\
\text { opinião }\end{array}$ & Ambos & Sim \\
\hline Pedro & $\begin{array}{l}\text { Persuasivo } \\
\text { Imparcial } \\
\text { Conhecedor } \\
\end{array}$ & $\begin{array}{c}\text { Reunir o máximo } \\
\text { de } \\
\text { informações } \\
\end{array}$ & $\begin{array}{l}\text { Terminá-las } \\
\text { rapidamente }\end{array}$ & $\begin{array}{l}\text { Lugares } \\
\text { agitados }\end{array}$ & $\begin{array}{l}\text { Expor } \\
\text { opinião }\end{array}$ & Proativo & Sim \\
\hline Ana & $\begin{array}{l}\text { Motivador } \\
\text { Dinâmico } \\
\text { Empático }\end{array}$ & $\begin{array}{c}\text { Reunir o máximo } \\
\text { de } \\
\text { informações }\end{array}$ & $\begin{array}{l}\text { Uma atividade } \\
\text { por vez }\end{array}$ & $\begin{array}{l}\text { Lugares } \\
\text { agitados }\end{array}$ & $\begin{array}{l}\text { Expor } \\
\text { opinião }\end{array}$ & Proativo & Sim \\
\hline Paula & $\begin{array}{c}\text { Íntegro } \\
\text { Comunicativ } \\
\text { o } \\
\text { Participativo }\end{array}$ & Avaliar o todo & $\begin{array}{l}\text { Uma atividade } \\
\text { por vez }\end{array}$ & $\begin{array}{l}\text { Lugares } \\
\text { tranquilos }\end{array}$ & $\begin{array}{l}\text { Expor } \\
\text { opinião }\end{array}$ & Proativo & $\operatorname{Sim}$ \\
\hline Marcos & $\begin{array}{c}\text { Conhecedor } \\
\text { Autocontrole } \\
\text { Empático } \\
\end{array}$ & $\begin{array}{c}\text { Reunir o máximo } \\
\text { de } \\
\text { informações }\end{array}$ & $\begin{array}{l}\text { Uma atividade } \\
\text { por vez }\end{array}$ & $\begin{array}{l}\text { Lugares } \\
\text { tranquilos }\end{array}$ & $\begin{array}{l}\text { Ouvir } \\
\text { primeiro }\end{array}$ & Proativo & Sim \\
\hline Maria & $\begin{array}{l}\text { Saber ouvir } \\
\text { Observador } \\
\text { Conhecedor }\end{array}$ & $\begin{array}{c}\text { Reunir o máximo } \\
\text { de } \\
\text { informações }\end{array}$ & Não definiu & $\begin{array}{l}\text { Lugares } \\
\text { agitados }\end{array}$ & $\begin{array}{l}\text { Expor } \\
\text { opinião }\end{array}$ & Ambos & $\operatorname{Sim}$ \\
\hline Roberto & $\begin{array}{c}\text { Dinâmico } \\
\text { Conhecedor } \\
\text { Motivador } \\
\end{array}$ & $\begin{array}{l}\text { Resolver de } \\
\text { imediato }\end{array}$ & $\begin{array}{l}\text { Uma atividade } \\
\text { por vez }\end{array}$ & $\begin{array}{l}\text { Lugares } \\
\text { agitados }\end{array}$ & $\begin{array}{l}\text { Expor } \\
\text { opinião }\end{array}$ & Proativo & $\operatorname{Sim}$ \\
\hline Gustavo & $\begin{array}{l}\text { Saber ouvir } \\
\text { Humildade } \\
\text { Conhecedor }\end{array}$ & $\begin{array}{c}\text { Reunir o máximo } \\
\text { de } \\
\text { informações }\end{array}$ & $\begin{array}{l}\text { Uma atividade } \\
\text { por vez }\end{array}$ & $\begin{array}{l}\text { Lugares } \\
\text { tranquilos }\end{array}$ & $\begin{array}{r}\text { Ouvir } \\
\text { primeiro }\end{array}$ & Proativo & $\operatorname{Sim}$ \\
\hline
\end{tabular}

Fonte: as autoras (2019).

Para se compreender a liderança é recomendável estudar a personalidade e o comportamento de líderes reconhecidos e descrever seus traços característicos e sua forma de agir (Bergamini, 2015; Crainer, 2006; Spector, 2005; Vergara 2003).

Desta forma, conforme pode-se notar pelo quadro 2, as características consideradas importantes para um bom líder segundo os entrevistados foram: saber ouvir, ter empatia e ser conhecedor tanto das atividades quanto do perfil do liderado, seguido do líder participativo, comunicativo, dinâmico, motivador e imparcial.

Importante destacar que os entrevistados declaram ser essencial conhecer as atividades sob sua responsabilidade e o perfil dos liderados observados nas falas a seguir:

Conhecer efetivamente uma atividade, ter todas as informações referentes ao executante da tarefa. O líder precisa saber pra quem está delegando de acordo com o perfil, por isso importante conhecer as características das pessoas (MARIA). 
Dificuldades e Potencialidades de Líderes Introvertidos em uma Indústria de Eletrodomésticos: um Estudo de Caso

\begin{abstract}
Conhecendo o perfil, o líder consegue distinguir as fraquezas e potenciais e, com isso, buscar trabalhar suas habilidades e, assim, conseguir repassar e compartilhar conhecimentos adquiridos ao longo da minha experiência (RENATO).

Conhecer é antecipar, ter visão macro e perceptível, conhecer o tipo de personalidade (PEDRO).

Conhecer é estar um passo à frente da equipe. O líder precisa ter conhecimento geral do setor, ser generalista, para não ficar refém do liderado e ele precisa ser especialista (ROBERTO).
\end{abstract}

Outras características mais enfatizadas foram: ter empatia e saber ouvir, estas peculiares do perfil introvertido e destacadas de imediato por 3 líderes. Segundo Costa (2015), a introversão é marcada pelo lado humano, valorizando as pessoas, sendo, por isso, bons ouvintes. Entre os entrevistados, Carla foi mais específica e declarou: "saber ouvir: é ser humano, é pensar nas pessoas, é se importar com elas". Gustavo afirmou veementemente que "o líder precisa ser ouvinte...”. E Marcos declarou: "ter um bom relacionamento com todos, seja com as pessoas que estão acima ou de baixo, ter controle e autocontrole".

Em relação à atitude do líder para resolver problemas, se este age de imediato ou procura reunir o máximo de informações para então decidir, a maioria dos respondentes destacou, no geral, que é importante buscar informações e não agir por impulso para evitar possíveis erros e, consequentemente, retrabalho nas atividades. Tal afirmação é explicitada nas falas a seguir:

\footnotetext{
Buscar reunir informações, pra não tomar decisão precipitada sem conhecer os fatos, sem saber se são reais ou não (ANA).

Cada caso é um caso; avaliar a situação como um todo é importante pra não se precipitar (PAULA).

Reunir o máximo de informações e pensar no impacto em cada ação, avaliando os riscos (RENATO).
}

Em oposição, apenas Lucas e Roberto salientaram que é importante resolver de imediato. Para Lucas, "é tentar resolver logo para não cair no esquecimento"; já Roberto considera que "por trabalhar na área de TI, as informações são emergenciais e, portanto, precisam ser resolvidas $\log 0^{\prime \prime}$.

Sobre maneiras de se trabalhar para executar tarefas, se de forma ponderada ou de maneira a terminá-las rapidamente, a maioria tem por preferência executar uma atividade por vez, conforme já dito anteriormente, para evitar erros. Os líderes Pedro e Lucas consideraram terminá-las rapidamente e Renato e Maria não definiram.

Com isso, o que se pode observar a respeito da tomada de decisão e da execução de tarefas é que ampla maioria tem por preferência executar uma atividade por vez e reunir o máximo de informações antes de tomar uma decisão, atitudes essas comuns ao introvertido. Cain (2012) explica que introvertidos trabalham de forma mais lenta e ponderada, gostam de focar em uma coisa por vez. Porém, apenas por essas afirmativas não se pode concluir que todos são introvertidos sem antes considerar todas as perguntas. Tal afirmação reforça o preconizado por Jung (1971), que ressalta não existir uma pessoa puramente introvertida ou extrovertida, mas uma inclinação maior para um dos traços.

A respeito da preferência por se trabalhar em lugares tranquilos ou agitados, houve uma diferença pequena, mais prevalecida por ambientes mais agitados tendo em vista o ambiente de 
Dificuldades e Potencialidades de Líderes Introvertidos em uma Indústria de Eletrodomésticos: um Estudo de Caso

trabalho no qual estão inseridos - uma indústria, em que a busca por resultado e dinamismo nas atividades criam um ambiente com maior interação. Para Pedro essa dinâmica gera uma agitação e nível de interação maior, onde a liderança acompanha os liderados. Maria acrescenta que pelo fato de ter trabalhado em obras a adaptação é muito mais fácil, enquanto Lucas e Ana destacam esses ambientes como propulsor de conhecimento não permitindo ficar com tempo ocioso.

Essa interação maior é característica citada por Ponte (2012) a respeito dos extrovertidos, que são sociais, expansivos, confiantes e energizam-se no contato com os outros. Em contraposição a ambientes agitados. Marcos afirma que é mais produtivo, já Gustavo sente menos a pressão do dia a dia e consegue pensar melhor sobre determinado assunto. Paula e Renato declararam que preferem ambientes mais tranquilos, no entanto, enfatizaram que conseguem adaptar-se facilmente ao local mais agitado.

Em relação à postura em reuniões, sobre apresentar seus pontos de vista de imediato ou ouvir primeiro, a maioria sente-se à vontade em expor suas ideias, de acordo com as falas de Ana, Pedro e Lucas:

\footnotetext{
Eu falo primeiro, principalmente se for algum problema da minha área, então eu saio falando logo para acionar as áreas responsáveis (ANA).

Eu exponho o que sinto de imediato, eu falo, e só depois eu ouço (PEDRO).

Reuniões são feitas pra falar, expor os pontos, então eu falo de imediato (LUCAS).
}

Já em contrapartida, Marcos prefere ouvir para se sentir mais seguro ao opinar e tomar uma decisão. Gustavo entende de mesma forma ao ressaltar que: "Prefiro ouvir fazendo minha avaliação e só depois me manifestar; evita conflito, não se expor sem respaldo, sem ter conhecimento". Carla destaca que: "Ouvir e depois chego num consenso, dessa forma me sinto mais aberta para opinar". Renato também prefere ouvir e avaliar para compreender o ponto de vista das pessoas.

O fato de os entrevistados destacarem a necessidade de ouvir inicialmente, está de acordo com Ponte (2012) que ressalta que as pessoas introvertidas são reservadas e prezam pela privacidade, tendendo a segurar as palavras e ouvindo cuidadosamente o que as pessoas dizem.

No tocante a preferências sobre quais pessoas liderar, entre aquelas com atitudes de obedecer às instruções ou que tomam iniciativa, a maior parte declarou preferir pessoas com iniciativa, pois tomam atitudes que, na maioria das vezes, não precisam da autorização do líder, são ágeis para encontrar soluções, são curiosos. Na sequência, sobre ouvir e implementar sugestões, as respostas foram unânimes em enfatizar que todos são receptivos a sugestões e que engajam seus liderados a trazer melhorias, como se vê:

Se o liderado já é conhecedor do conteúdo, já pode tomar decisões e cobrar as áreas responsáveis. É necessário ter confiança porque minha liderança não é centralizadora: eu delego e confio (MARIA).

Eu não centralizo as atividades, gosto do compartilhamento de ideias de pessoas com iniciativa. Temos um programa de melhoria contínua, cada pessoa traz suas ideias e priorizamos as ideias em escala de melhorias, ideias de maneira culturizada (PEDRO). Quem tem atitude é perfeito. É importante tomar para si os problemas e tentar resolvêlos. Sugestões são sempre bem-vindas (PAULA). 
Dificuldades e Potencialidades de Líderes Introvertidos em uma Indústria de Eletrodomésticos: um Estudo de Caso

Vale ressaltar que, mesmo havendo variação nas respostas, em que ora a atitude parece ser do perfil introvertido e outrora extrovertido, como já explicado anteriormente por Jung (1971), não existe uma pessoa puramente extrovertida ou introvertida, mas apenas uma inclinação maior para um dos traços.

Dentre todas as respostas, os que maior tiveram inclinação à introversão foram os líderes Carla, Gustavo e Marcos. É relevante frisar que, durante a entrevista, os três mostraram-se bastante reservados, respondendo às questões com cuidado e ouvindo atentamente as informações relatadas. Apesar de os introvertidos gostarem de trabalhar em ambientes mais tranquilos, Carla destacou que, por trabalhar em um ambiente naturalmente mais agitado dada a área de produção, na qual há necessidade de se alcançarem as metas diárias, muitas atividades e uma quantidade elevada de pessoas, precisou se adaptar e acabou gostando. Ela destaca: "tive que me adaptar ao meio e acabei gostando, são novos desafios que vão surgindo no dia-a-dia". Isto não quer dizer que Carla não seja introvertida, apenas que este perfil se adapta ao meio, esfera essa comum aos extrovertidos.

\subsection{Percepções dos líderes a respeito do perfil introvertido}

Para analisar a percepção dos 3 líderes introvertidos sobre esse tipo de perfil, foi realizada uma investigação de suas respostas, que, para melhor entendimento, foram agrupadas em traços de personalidade, atitudes e relacionamentos.

Este perfil possui características voltadas para a valorização do fator humano. Outros traços destacados, além dos já descritos anteriormente, são: ser tolerante, ter humildade, ser empático, ter controle e autocontrole, assumir suas responsabilidades, ser imparcial, ter conhecimento técnico sobre a atividade desempenhada, além de estar atento aos acontecimentos diários. Tais características podem ser observadas nas falas a seguir:

Ter controle sobre a situação e ter autocontrole sobre mim mesmo, principalmente no meu comportamento com as pessoas, assim como assumir minhas responsabilidades, antenado às coisas que acontecem e a capacidade para lidar com as divergências são essenciais no meu papel de gestor (MARCOS).

Ser tolerante, humilde, me torna mais humano e próximo dos meus liderados e, para mim, isso é muito importante. E também conhecimento de causa (GUSTAVO).

É muito importante ser imparcial para não ser injusta com ninguém e ter conhecimento técnico (CARLA).

No geral, líderes introvertidos prezam pelas relações interpessoais. A perspectiva das relações interpessoais também foi ressaltada nos estudos de liderança realizado por Hersey e Blanchard (1986).

No entanto, o contato em excesso exaure-os em determinado momento. Dados da revista Frontiers in Human Neuroscience destacados por Goshe (2013) explicam que, enquanto os extrovertidos sentem a dopamina, hormônio relacionado ao prazer dentro do ambiente, os introvertidos tendem a não sentir essa alteração porque não processam as recompensas com a mesma intensidade.

O fato de a tomada de decisões ser mais comedida deve-se ao fato de não gostarem de exposição e isto não tem relação necessária com o medo, apenas faz parte de suas personalidades. 
Dificuldades e Potencialidades de Líderes Introvertidos em uma Indústria de Eletrodomésticos: um Estudo de Caso

Vale ressaltar que a preferência de líderes introvertidos por liderados proativos é justificada pela pesquisa da professora Gino (2015) e sua equipe. Os liderados proativos são mais eficientes e apresentam um desempenho superior porque são ótimos ouvintes e levam em consideração as sugestões apresentadas pelos liderados. Gustavo deixa clara a importância das sugestões justamente para fazer a avaliação e saber se quem a apresenta tem conhecimento de fato sobre o assunto. Já para Marcos ter pessoas comunicativas em sua equipe é bom porque estas buscam informações mais detalhadas trazendo engajamento para todo o grupo, por isso a necessidade de avaliar as ideias de todos. Carla corrobora que liderados que tomam iniciativa dão suporte em sua ausência, porque procuram aprender e conhecer todo o processo.

Assim, pode-se concluir que o líder introvertido tem características presentes em uma liderança transformacional, pois, conforme Bass (1985), o principal objetivo é aumentar a consciência do grupo através do estímulo ao crescimento individual, buscando alinhar mais as expectativas individuais e organizacionais.

\subsection{Qualidades e dificuldades encontradas}

Os líderes introvertidos pesquisados destacaram como pontos positivos as decisões mais assertivas e analíticas, falar menos e ser reservado. As falas a seguir retratam tais observações:

Por eu ser mais reservada, as pessoas me veem com muita seriedade, com mais
respeito e, por conta disso, tenho mais liberdade para opinar e minha opinião vai ser
levada em consideração (CARLA).
Falando menos eu me torno mais preciso e evita o ruído na comunicação, trazendo
clareza (MARCOS).
Procuro sempre ser claro, objetivo e ir direto ao ponto sem ficar falando demais.
Assumo uma postura mais assertiva. Eu faço uma análise detalhada dos prós e contras
e isso é importante até mesmo pra identificar os perfis dos meus liderados
(GUSTAVO).

Interessante notar que o falar demais os esgota justamente por conta de sua energia estar focada mais para a subjetividade, característica mais ligada à introversão do que ao ambiente externo. Quanto aos pontos negativos, podem-se citar a dificuldade em aproximação; a falta de valorização e não cultivar muitas amizades. Os entrevistados ressaltaram que:

\footnotetext{
Não cultivar muitas amizades talvez não seja tão bom, porque é importante conhecer e aprender com as pessoas por conta do ambiente em que estamos inseridos. Já tentei fazer isso, mas tem momentos que não sei mais o que dizer (MARCOS).

Por conta da seriedade, em ser mais reservada, isso dificulta um pouco o relacionamento com algumas pessoas porque elas tendem a não se aproximar por causa disso (CARLA).

Às vezes penso que, por ser introvertido, não sou valorizado; por ser mais na minha, tenho sempre que apresentar resultados superiores aos extrovertidos pra que eu então seja notado. Talvez isso de fato tenha a ver porque os extrovertidos têm a falar demais, chamam atenção, mas eu acredito que nem sempre falar demais quer dizer que a pessoa seja realmente conhecedora de algo (GUSTAVO).
}

A declaração de Gustavo ratifica o que Nobel (2010) já havia observado, ou seja, a percepção que se tem no geral é de que as pessoas falantes são mais inteligentes do que as quietas. Moutafi (2003) corrobora o entendimento de que introvertido tem um melhor desempenho que os 
Dificuldades e Potencialidades de Líderes Introvertidos em uma Indústria de Eletrodomésticos: um Estudo de Caso

extrovertidos no teste Watson-Glaser de pensamento crítico no mundo dos negócios, para promoções e contratações. Eles demonstram excelência na resolução de problemas.

Importante observar na fala de Carla o termo "ser mais reservada": para a maioria das pessoas, soa como tímida, o que também é refutado por Granneman (2017), sendo um pensamento equivocado uma vez que, apesar de evitarem interações sociais, as razões são diferentes. Enquanto os introvertidos sentem-se cansados, os tímidos tendem a sentir angústia, vergonha. Isso costuma ser mais comum nos introvertidos e tem relação com os sinais que recebem da sociedade de que as pessoas preferem as personalidades extrovertidas. Por conta disso, sentemse mal em pensar demais e precisa de mais tempo para refletir, levando à timidez por conta do medo e do julgamento. A dificuldade de Marcos em relacionar-se com muitas pessoas justificase pelo fato de ser inerente do introvertido. Ponte (2012) também relata isso destacando que os líderes introvertidos se sentem confortáveis quando sozinhos ou com poucas pessoas porque o contato com muitas delas tende a ser cansativo. Por isso, sentem-se energizados quando trabalham de forma silenciosa e solitária.

Assim, o que se percebe é que este perfil é pouco explorado justamente pelo ideal da extroversão, ao qual se faz uma supervalorização dos líderes com discursos eloquentes, sendo considerados mais inteligentes, competentes e simpáticos. Estilo esse tão atraente, transformase num padrão para quem quer ter sucesso (Cain, 2012). Desta forma, é necessário que ambos os perfis tenham as mesmas oportunidades porque podem contribuir significativamente para $o$ sucesso da organização.

\section{CONCLUSÃO}

Este estudo possibilitou uma análise das potencialidades e dificuldades do líder introvertido em uma organização. Para isso, foram realizadas entrevistas com dez pessoas entre líderes, supervisores e gerentes.

Através dos relatos dos entrevistados, constatou-se que líderes ouvintes e empáticos que conhecem seus liderados e as atividades que estão sob sua responsabilidade são características consideradas importantes pelos líderes. Outras características apontadas são: líder participativo, comunicativo, dinâmico, motivador e imparcial. De maneira geral, os respondentes apresentaram semelhanças em suas respostas, destacando características comuns a pessoas extrovertidas, o que é justificável principalmente em se tratando de uma indústria, ambiente comum aos extrovertidos e de fácil adaptação.

Notou-se que os três líderes introvertidos também possuem traços de extroversão, mas que se sobressaem na introversão justamente pelo fato de terem uma propensão maior a ouvir e a valorizar o fator humano, características que, quando combinadas a uma equipe proativa, tendem a apresentar resultados acima da média, principalmente por levarem em consideração as sugestões indicadas pelos seus liderados.

Os pontos positivos a serem destacados do perfil introvertido são: decisões mais assertivas e analíticas, características que, no ambiente organizacional, podem representar um diferencial competitivo uma vez que agem de forma pacífica em situações de conflitos, demostrando 
Dificuldades e Potencialidades de Líderes Introvertidos em uma Indústria de Eletrodomésticos: um Estudo de Caso

segurança e baseando suas decisões em fatos. Buscam, assim, soluções de maneira equilibrada e construtiva.

Por outro lado, o fato de os introvertidos serem quietos e comportarem-se de maneira comedida traz como consequências a dificuldade de relacionamentos com colegas de trabalho, a falta de valorização própria e não cultivar muitas amizades, sendo pontos a serem melhorados. Essa falta de contato é explicada porque eles sentem-se mais confortáveis quando sozinhos ou com poucas pessoas.

Apesar de os líderes introvertidos encontrados serem minoria, pode-se considerar um avanço que refuta o ideal da extroversão de que o mundo dos negócios é um meio para líderes que possuem o discurso eloquente, que são expansivos e falantes. Mesmo que o introvertido seja o oposto, ambos podem trabalhar lado a lado e potencializar o que cada um tem de melhor. Desta forma, descobrir essas características possibilita conhecer este perfil tão pouco valorizado e compreender que podem ser excelentes líderes. Tanto introvertidos quanto extrovertidos precisam ter as mesmas oportunidades de mostrar suas habilidades.

Como contribuição teórica, este trabalho colabora com o avanço do conhecimento no que diz respeito à liderança introvertida no segmento industrial, ao passo que traz uma visão mais clara a respeito deste perfil até então pouco conhecido. Como contribuição prática, esta pesquisa ajuda na identificação dos perfis para atingir resultados e desenvolver potenciais.

Para pesquisas futuras, sugerem-se verificar a relação das habilidades e competências dos líderes introvertidos e extrovertidos com o nível de sucesso da empresa, investigar as habilidades e dificuldades apresentadas pelo líder extrovertido, assim como dos liderados, e conhecer o perfil dos liderados introvertidos em outras organizações.

\section{REFERÊNCIAS}

Alves, S. (2010). Liderança organizacional: discussão sobre um conceito-chave à administração. Revista Pensamento Contemporâneo em Administração. v. 4, n. 1, p. 43 53.

Bardin, L. (2016). Análise de conteúdo. São Paulo: Edições 70.

Bass, B. M. (1985). Leadership and performance: beyound expectations. New York: Free Press.

Bass, B. M., \& Avolio, B. J. (1994). Shatter the glass ceiling: women may make better managers. Human Resource Management, New York: v. 33, n. 4; p. 549- 561.

Benevides, V. L. A. (2010). Os estilos de liderança e as principais táticas de influência utilizadas pelos líderes brasileiros. Tese (Doutorado) - Fundação Getúlio Vargas, Rio de Janeiro.

Bergamini, C. W. (1994). Liderança: a administração do sentido. Revista de Administração de Empresas, 34(3), 102-114.

Bergamini, C. W. (2015). Psicologia aplicada à administração de empresas: psicologia do comportamento organizacional ( $5^{\mathrm{a}}$. ed.). São Paulo: Atlas.

Bowditch, J. L., \& Buono, A. F. (2002). Elementos do comportamento organizacional. São Paulo: Pioneira Thomson. 
Dificuldades e Potencialidades de Líderes Introvertidos em uma Indústria de Eletrodomésticos: um Estudo de Caso

Burns, J. M. (2003). Transforming leadership. New York: Atlantic Monthly Press.

Cain, S. (2012). O poder dos quietos: como os tímidos e introvertidos podem mudar o mundo que não para de falar. Tradução Ana Carolina Bento Ribeiro. Rio de Janeiro: Agir.

Champoux, J. E. (2011). Organizational behavior: integrating individuals, groups, and organization. ( $4^{\mathrm{a}}$. ed.). New York: Routledge. $528 \mathrm{p}$.

Collins, J. (2013). Empresas feitas para vencer.( $6^{\mathrm{a}}$. ed.). Rio de Janeiro: Campus.

Costa, P.H. (2015). Liderança: dificuldades e potencialidades de um líder introvertido nas organizações. ENIAC Pesquisa, Guarulhos (SP), p.81-98, v. 4, n. 1.

Crainer. S. (2000). Os grandes pensadores da administração: as ideias que revolucionaram o mundo dos negócios. São Paulo: Futura.

Dorneles, E.L., Salvagni, J., \& Nodari, C.N. (2017). A liderança como diferencial nas organizações: um estudo de caso sobre a percepção dos gestores. HOLOS, Ano 33, Vol. 08.

Fiedler, F. E. (1967). A theory of leadership effectiveness. New York: McGraw-Hill.

Fisher, S. G., Macrosson, W.D.K., \& Semple, J.H. (2001) Control and belbin's team roles. Personnel Review, Farnborough, v.30, n.5, p.578-588.

Ghose, T. (2013). Why extroverts like parties and introverts avoid crowds. Publicado em junho de 2013, acessado em: 07 de setembro de 2019. Disponível em:

< https://www.livescience.com/37427-extroverts-have-different-brain-processes.html>.

Gino, F. (2015). Introverts, extroverts, and the complexities of team dynamics. . Publicado em março de 2015, acessado em: 06 de outubro de 2019. Disponível em: <https://hbr.org/2015/03/introverts-extroverts-and-the-complexities-of-team-dynamics >.

Granneman, J. (2017). The secret lives of introverts: Inside our Hidden World. Skyhorse.

Hersey, Paul, \& Blanchard, Kenneth. (1986). Psicologia para administradores: a teoria e as técnicas da liderança situacional. São Paulo: Pedagógica e Universitária.

House, R. J. (1971). A path-goal theory of leader effectiveness. Administrative Science Quarterly, n. 16, p. 321-328.

Hunter, J. (2004). O monge e o executivo: uma história sobre essência da liderança. Rio de Janeiro: Sextante.

Jung, C. G. (1971). Tipos psicológicos. Vozes. (Obras Completas - Vol.VI).

Kirkpatrick, S. A., \& Locke, E. A. (1991). Leadership: do traits matter? The Executive, v. 5, n. 2, p. 48-60. Publicado em 1971, acessado em: 25 de outubro de 2019. Disponível em: < https://sites.fas.harvard.edu/ soc186/AssignedReadings/Kirkpatrick-Traits.pdf.>.

Loureiro, G. (1999). A Systems Engineering and Concurrent Engineering Framework: For the Integrated Development of Complex Products. $450 \mathrm{f}$. Tese (Doutorado) - Curso de Philosophy, Departamento de Department Of Manufacturing Engineering, Loughborough University, Leicestershire,uk.

Mello, F. B. (2013). Sob o domínio do medo. Administradores, João Pessoa, v.21, p. 36-41, jun / jul.

Minayo, M. C. (2007). Pesquisa social: teoria método e criatividade. (25a . ed.). Petrópolis: Editora Vozes.

Morais, F. L. (2016). O desafio das lideranças: assegurar a produtividade com pessoas de diferentes gerações. ReCaPe Revista de Carreiras e Pessoas São Paulo. Volume VI Número 02 - Mai/Jun/Jul/Ago.

Moutafi, J., Furnham, A., \& Crump, J. (2003). Demographic and personality predictor of intelligence: A study using the NEO Personality inventory and the Myers-Briggs type indicator. European Journal of Personality 17, n.1. p. 79-84. 
Dificuldades e Potencialidades de Líderes Introvertidos em uma Indústria de Eletrodomésticos: um Estudo de Caso

Nobel, C. (2010). Introverts: The Best leaders for proactive employees. Harvard business school working knowledge: Boston. Publicado em outubro de 2010, acessado em: 10 de setembro de 2019 . Disponível em: <https://hbswk.hbs.edu/item/introverts-the-best-leadersfor-proactive-employees>

Peretomode, O. (2012). Situational and contingency theories of leadership: are they the same. IOSR Journal of Business and Management, 4(3), 13-17.

Ponte, T. M. (2012). Perfil psicológico e interesses profissionais de estudantes de odontologia. Tese (Doutorado em Odontologia Social) - USP, São Paulo.

Ramos, L. T. G, Corrêa, M. R. B., Silva, S. W., Pereira, M. de O., Lemes, P. T., \& Magalhães, S. R. (2016). Um estudo sobre a liderança situacional e as suas contribuições para o desenvolvimento das organizações. Revista da Universidade Vale do Rio Verde, Três Corações, v. 14, n. 1, p. 1003-1014, jan./jul.

Rezende, F. V., Carvalho N., A. M., \& Tanure, B. A. (2014). A percepção de executivos e executivas sobre estilos de liderança. Reuna, v. 19, n. 4, p. 107-130.

Robbins, S. P. (2014). Comportamento organizacional. 14 ed. São Paulo: Prentice Hall.

Sadler, P. (2003). Leadership and organizational learning. In: DIEKERS, Meinolf. Handbook of organizational learning and knowledge. Oxford: Oxford University Press, Cap.18, p.415-427.

Santos, E. M. (2016). Tímidos e introvertidos: como os gestores podem aproveitar todo este potencial? In: Cneg - Xii Congresso Nacional de Excelência em Gestão, Anais eletrônicos. Publicado em 2016, acessado em: 13 de junho de 2019. Disponível em <http://www.inovarse.org/sites/default/files/T16_M_042.pdf >.

Spector, P. E. (2005). Psicologia nas organizações. São Paulo: Saraiva.

Stefano, S. R., Andrade, S. M. de, Gonçalves, D. M., \& Valori, L. C. (2008) Liderança orientada para resultados: um estudo de múltiplos casos em instituições financeiras. Revista Capital Científico, Guarapuava - PR v.6 n.1 p.199-222 jan./dez.

Sugahara, C., Jannuzzi, C., \& Falsarella, O. (2018). Os componentes do ambiente interno e externo na geração da inovação nas organizações. Revista da Micro e Pequena Empresa, Campo Limpo Paulista, v.12, n.1 p.51-66.

Triviños, A. N. S. (1994). Introdução à pesquisa em ciências sociais: a pesquisa qualitativa em educação. São Paulo: Atlas.

Vergara, S. C. (2003). Gestão de pessoas. 3. ed. São Paulo: Atlas.

Vergara, S. C. (2005). Métodos de pesquisa em administração. São Paulo: Atlas.

Yin, R. K. (2006). Estudo de caso: planejamento e métodos. 3. ed. Porto alegre: Bookman. 